\title{
WSGC Collegiate Rocket Competition Design Analysis - Team ChlAM
}

\author{
Max Strassman, Chloe Tinius, Andrew Udelhoven \\ University of Wisconsin - Madison \\ Department of Engineering Physics
}

\begin{abstract}
The WSGC Collegiate Rocket Competition's 2012 launch challenged teams to launch a single stage high-power rocket as close to $3000 \mathrm{ft}$ in the air while transmitting live video for the entire ascent. Our team designed and successfully launched a roughly 5 foot tall rocket for the competition on a $\$ 1000$ budget. With the aid of simulation software and our own calculations, our rocket had a safe and stable launch to $2479 \mathrm{ft}$, lower than our expected $3000 \mathrm{ft}$. Error was likely caused by the strong wind and rainy conditions during the launch, which add drag. In addition, we made assumptions in our calculations about the rocket's drag coefficient, which may not have been accurate. We were satisfied with the success of our first high-power rocket and learned a lot that can be carried over to next year's competition.
\end{abstract}

\section{COMPETITION PARAMETERS}

The Collegiate Rocket Competition sponsored by WSGC is an annual competition open to undergraduate and graduate students from Wisconsin universities. Both engineering and nonengineering students are permitted to take part in the competition, but compete in separate categories. Each year, WSGC applies different parameters and challenges for the competition, making the focuses of a rocket's design different from year to year. For the 2011-12 competition, the challenge was to launch a single-stage high power rocket as close to 3000 feet as possible using one of several motor options. In addition, the rocket was required to transmit a live video signal to the ground during the ascent. The rocket was to have a successful parachute deployment using an electronic deployment system and be recovered in flyable condition.

\section{DESIGN FEATURES}

Our rocket design was fairly straightforward for a high power rocket. Figure 1 details the rocket design and layout. The rocket was 61 inches long and used a 3.9-inch diameter body tube. Starting at the nose of the rocket, we used a standard high-power rocket nosecone attached to a BlueTube body tube. BlueTube is a very strong and durable paper fiber used on tank shells. Within the upper section of the main body tube is the electronics bay, a protective casing used to store the altimeter to record flight data and deploy the parachute. The altimeter used in our rocket was the PerfectFlite Stratologger, which recorded altitude, velocity and acceleration of the rocket during the flight using an accelerometer and the outside air pressure. Upon rocket recovery, we were able to retrieve the information from our altimeter and analyze the rocket's performance using a computer. The altimeter also deployed the parachute when the rocket reached the top of its flight path using a gunpowder charge fixed to the inside of the rocket. The rocket splits in two at the electronics bay with the upper and lower section tied together using a Kevlar shock cord. The lower section of the rocket contains the parachute and motor. Our rocket used a 44" diameter parachute, which was protected on either side by two small Nomex blankets so that it would not be burned when the parachute deployment charge detonated. At the bottom of the rocket is the motor, which was secured by an engine cap and slid into a smaller 
diameter BlueTube. The smaller tube was secured to the body tube by two plywood rings. The motor used for our rocket was a Cesaroni I-285. Attached to the motor tube is an aluminum fin can, which has channels on the exterior to facilitate correct fin orientation. Three G-10 fiberglass fins were mounted at the base of the rocket. On the exterior of the rocket, a single 1.14 " diameter tube and nose cone were glued to the main body to house the onboard camera. The camera used was made by BoosterVision and had a range extender to increase reception beyond 5000 feet. The camera itself is approximately an inch cube and attaches to a $9 \mathrm{~V}$ battery. The camera looked down the body of the rocket towards the ground.

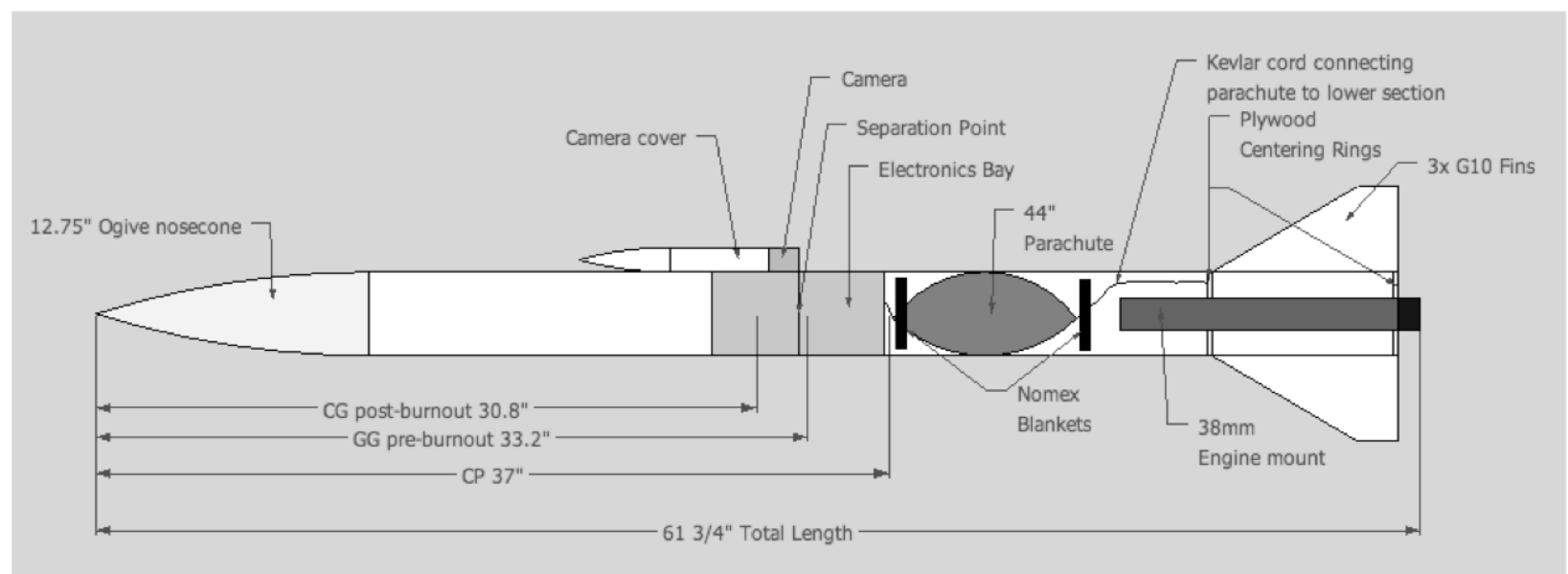

Figure 1. Rocket layout and design

\section{ROCKET STABILITY}

A major concern for any rocket is stability. If a rocket is unstable, it may have a chaotic flight path and could fly very far horizontally, causing it to become potentially dangerous and likely making it arduous to recover. The rule of thumb for stability is that a stable rocket will generally have the center of pressure (labeled CP in Figure 1) between one and two body diameters, or calibers, behind the center of gravity (labeled CG in Figure 1). A difference of less than one body diameter is generally marginally stable and a difference greater than two is generally overstable. An over-stable rocket will turn into the wind, reducing its maximum altitude. If the center of pressure is ahead of the center of gravity, the rocket is likely to be unstable. During flight, the center of pressure does not change, but because the rocket loses propellant mass, the center of gravity shifts forward. If the mass of the propellant is a significant percentage of the rocket's total mass, stability can be affected significantly. Before and after burnout, the distance between our center of gravity and center of pressure increased from approximately one body diameter (marginally stable) to about 1.6 diameters (stable). For our calculations, we used RockSim, a rocket simulation software, to determine our rocket stability.

\section{ANTICIPATED PERFORMANCE}

Predicted Altitude Rocket performance was modeled using RockSim and was validated using Microsoft Excel and Engineering Equation Solver (EES). Our main points of focus were maximum altitude and maximum acceleration. The altitude that was expected under fair conditions with negligible wind was 3307 feet from RockSim, while the altitude that the rocket was expected to reach based on our Excel simulation was 2935 feet. This discrepancy between 
the two altitudes was most definitely non-negligible, and testing under ideal conditions would have helped confirm which method was most accurate. Below are graphs from both simulations.

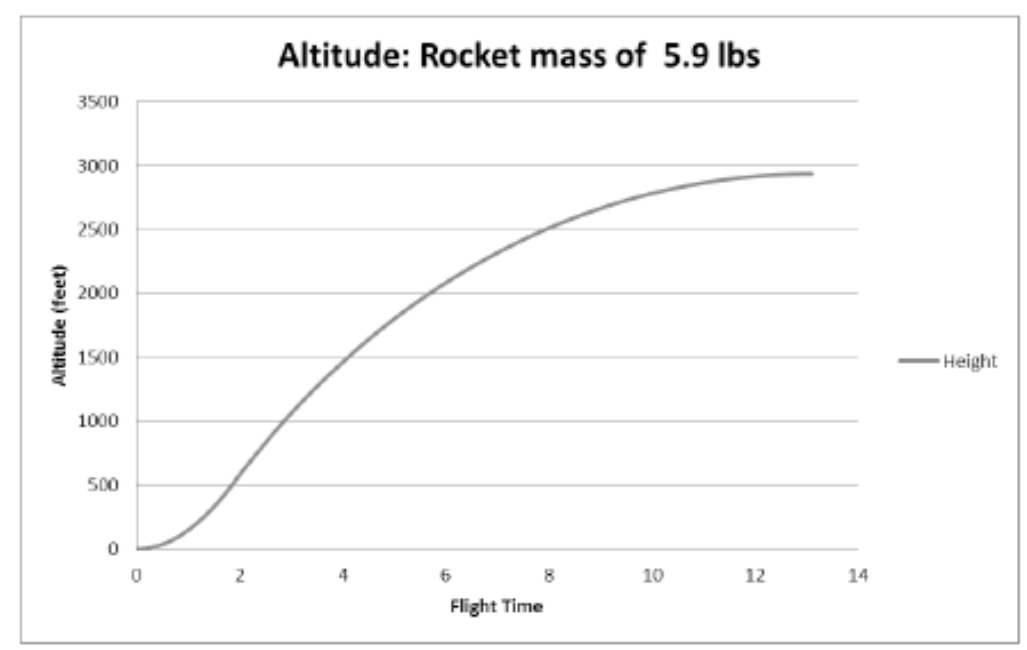

Figure 2. Predicted altitude from EES/Excel simulation

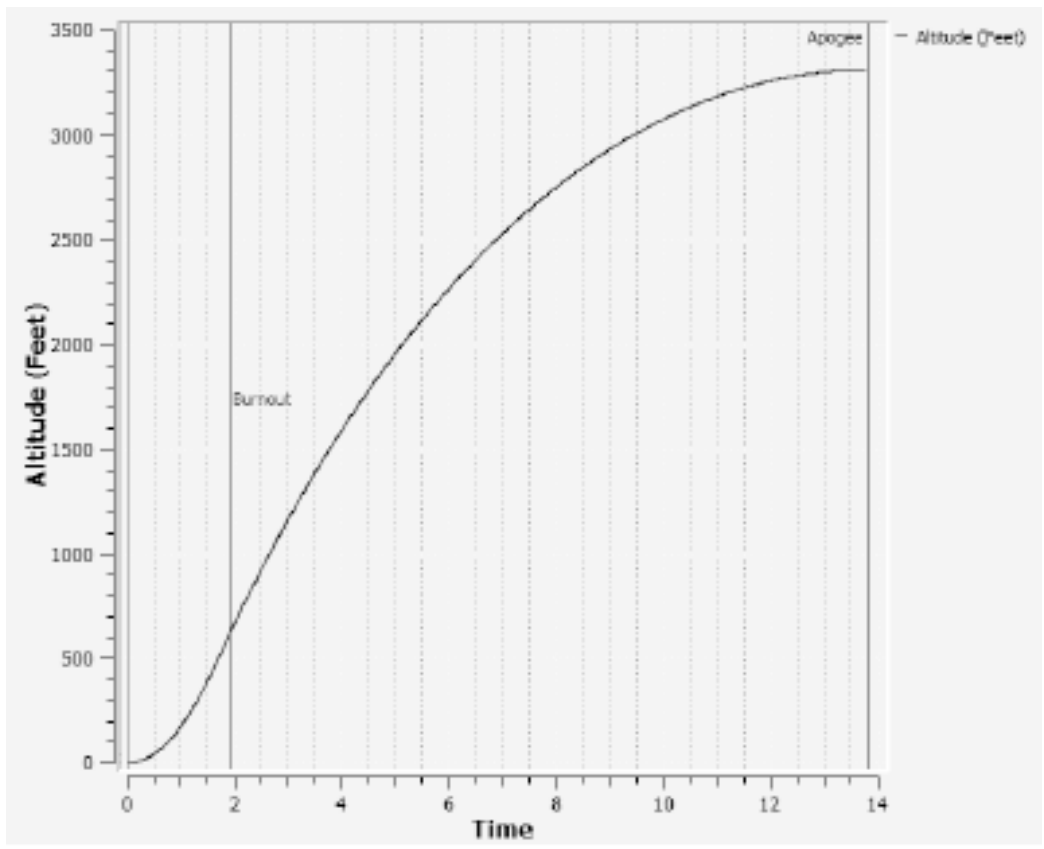

Figure 3. Predicted altitude from RockSim simulation

Predicted Acceleration Using the EES/Excel simulation, the point at which maximum acceleration would be expected would be the moment the engine begins to fire. This is because the velocity of the rocket is zero, so there is no drag force and the motor thrust was assumed to be constant for the sake of simplicity. Taking those assumptions to be true by force equals mass times acceleration, the maximum acceleration is $316.8 \mathrm{ft} / \mathrm{s}^{2}$ (using an average thrust of $285 \mathrm{~N}$ ). The simulation performed in RockSim gave the maximum acceleration to be $399 \mathrm{ft} / \mathrm{s}^{2}$. The difference in the accelerations arises because RockSim does not take the thrust of the engines to be constant. Since RockSim allows for variable 
thrust, the accepted value for the maximum acceleration is $399 \mathrm{ft} / \mathrm{s}^{2}$.

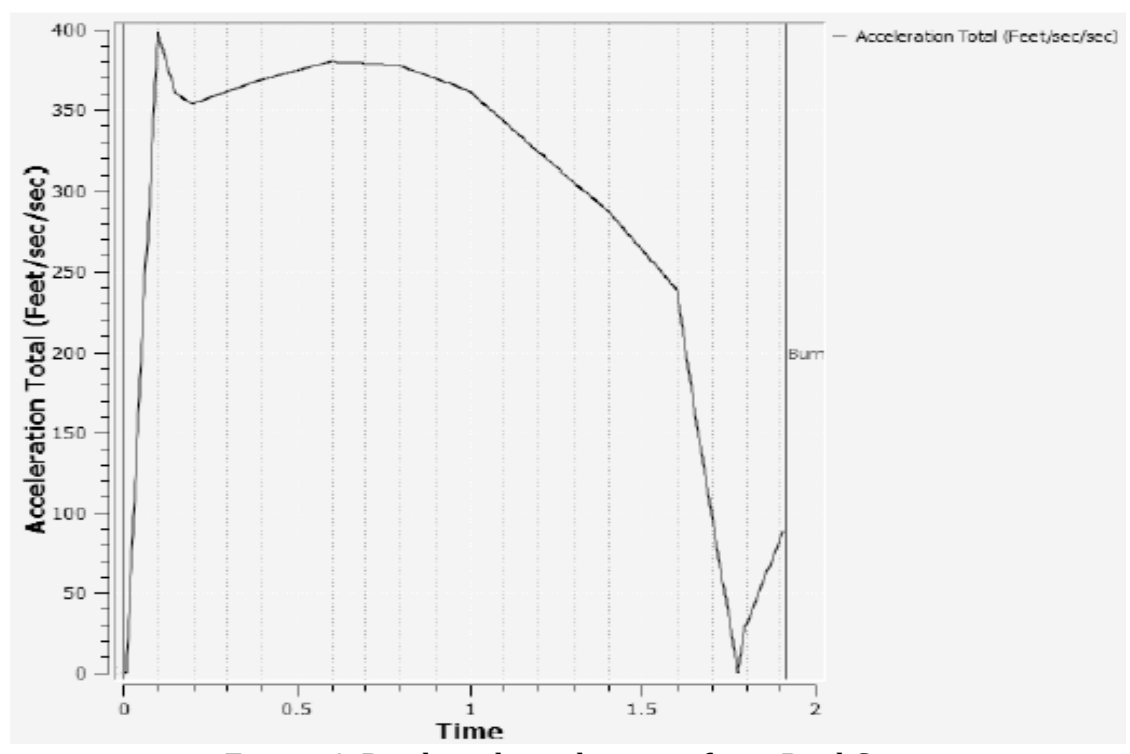

Figure 4. Predicted acceleration from RockSim

\section{ACTUAL PERFORMANCE}

Conditions on launch day (April 28, 2012) were less than ideal with rain and strong wind applying significant drag to the rocket, causing us to significantly undershoot both of our numbers for predicted maximum altitude.

Regarding operation, the rocket worked as expected, being stable throughout the flight with video transmission for nearly the entire ascent and a successful parachute deployment at apogee. Because of a strong crosswind, the rocket drifted over a mile away from the launch site and was found 60 feet up in a tree. The rocket remained structurally intact and could be flown again.

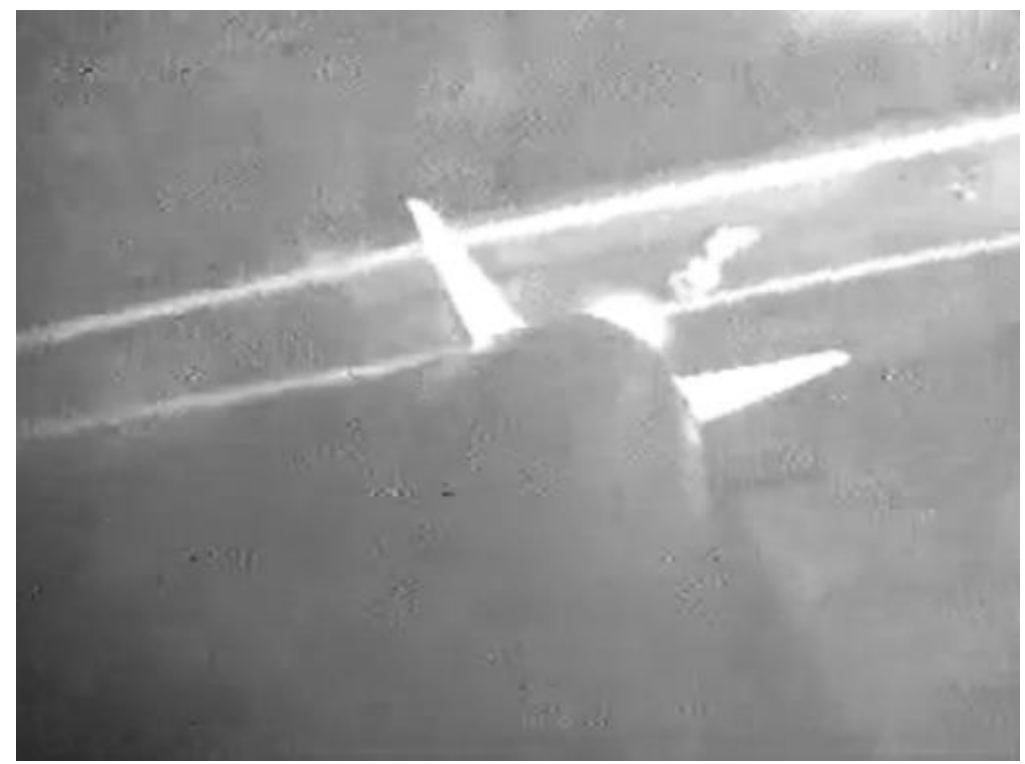

Figure 5. Actual launch footage from the onboard camera 
Maximum Altitude The maximum altitude achieved by the rocket $(2479 \mathrm{ft}$ ) differed greatly ( $21 \%$ error) from the expected maximum altitude $(3000 \mathrm{ft})$. In accounting for discrepancies between our calculations and the actual results, a few probable sources of error stick out. First, since our simulations and calculations assumed we would launch in ideal or near ideal conditions, the increased drag caused by weather lessened our altitude. Secondly, several assumptions were made in our calculations to simplify them, which may have increased error significantly. We assumed a drag coefficient of .33, but wouldn't be able to confirm this as accurate without testing. It was observed in the footage of the launch taken by the authors that the rocket does not travel vertically off of the pad. There are two likely causes for this: drag forces on the rocket were not balanced, or the rocket was unstable. The drag forces on the rocket were not balanced because an external pod was attached to the exterior of the rocket in order to house the camera/transmitter. The stability of the rocket was also questionable. The rocket had a margin of one caliber after burnout, which is acceptable, but before burnout, the distance between the center of pressure and center of gravity was too small (approximately .75 calibers.) Because the margin was small, perturbations in the flight would be able to grow faster and make the assumption of vertical flight invalid. The rocket was never wind tunnel tested, nor flight tested before launch day. This left us with no accurate way to determine the coefficient of drag (and therefore maximum altitude and acceleration). This left the team to trust the value based off of expected values from the simulation software RockSim, which was not ideal.

Maximum Acceleration The maximum acceleration $\left(515 \mathrm{ft} / \mathrm{s}^{2}\right.$ ) also differed greatly (29\%) from the predicted value $\left(399 \mathrm{ft} / \mathrm{s}^{2}\right)$. This was due to similar reasons as the differences between the maximum predicted altitude and the maximum achieved altitude. The model created was actually modeling a slightly different rocket. The model that was created had two side pods (initial design), one for the camera and the other for symmetry, instead of only one (flight configuration). Because there was one less pod, the drag force on the rocket was less and the rocket could achieve a higher rate of acceleration. The coefficient of drag used in the model is also inaccurate. For the maximum acceleration RockSim was used. RockSim calculates the coefficient of drag and it even varies with velocity, but experience has shown that calculated values from RockSim can be wildly inaccurate.

Table 1. Predicted and actual performance values

\begin{tabular}{|l|l|l|}
\hline & Predicted Value & Actual Value \\
\hline Maximum Altitude & $3000 \mathrm{ft}$ & $2479 \mathrm{ft}$ \\
\hline Maximum Acceleration & $399 \mathrm{ft} / \mathrm{s}^{2}$ & $515 \mathrm{ft} / \mathrm{s}^{2}$ \\
\hline Time to Apogee & $13.2 \mathrm{~s}$ & $12.8 \mathrm{~s}$ \\
\hline Good video time & $13.2 \mathrm{~s}$ & $8 \mathrm{~s}$ \\
\hline
\end{tabular}

\section{CONCLUSIONS}

Overall, our team is satisfied with our successful launch and recovery of our first-ever highpower rocket. There are several aspects of design and simulation that we can carry over to future rockets. First, we learned not to trust RockSim for extremely accurate results and instead will try to use our own calculations. In addition, to reduce the distance that the rocket travels under parachute, we will use a dual parachute deployment system with a small parachute deploying at 
apogee and the main parachute deploying later in the descent. Lastly, we will put a GPS tracker on board so that we can find the rocket more easily.

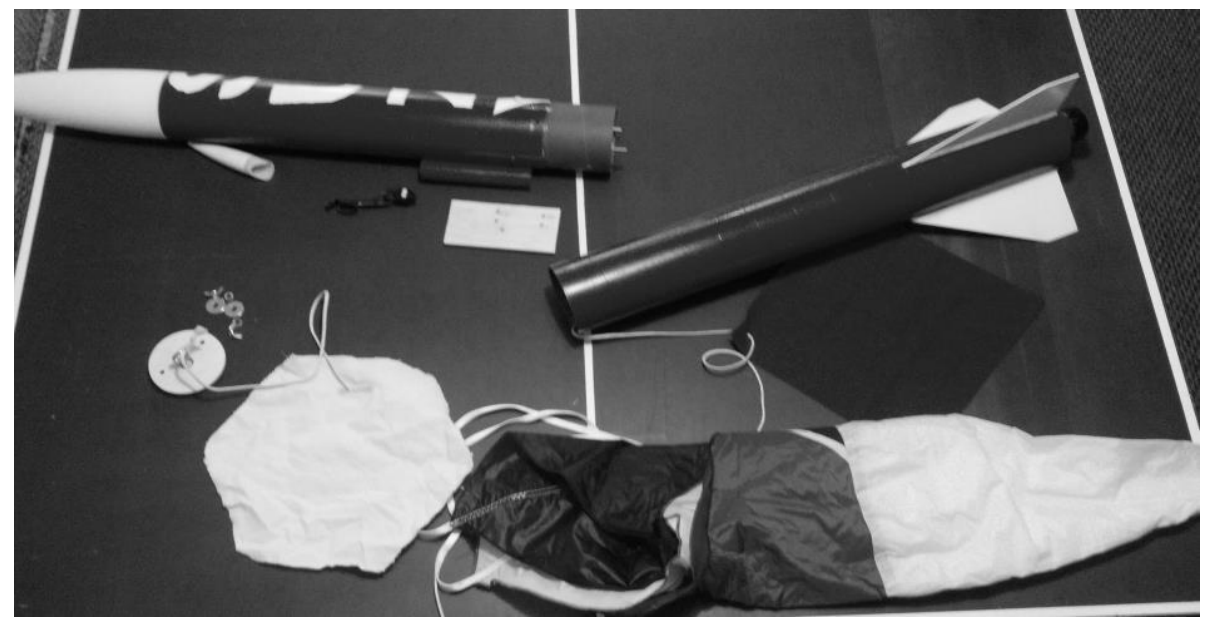

Figure 6. Disassembled picture of the rocket

The authors would like to acknowledge Wisconsin Space Grant Consortium for their sponsorship of the Collegiate Rocket Competition as well as Dr. Suzannah Sandrik at the University of Wisconsin - Madison for her advising during the design process. 